\title{
Progenitor Cells for the Prostate Epithelium: Roles in Development, Regeneration, and Cancer
}

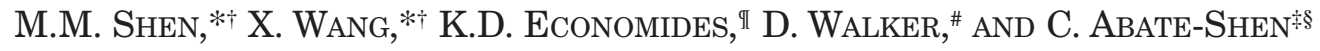 \\ *Departments of Medicine, ${ }^{*}$ Genetics and Development, ${ }^{*}$ Urology, and ${ }^{\S}$ Pathology, Herbert Irving \\ Comprehensive Cancer Center, Columbia University College of Physicians \& Surgeons, New York, \\ New York 10032; "Department of Biological Sciences, Sanofi-Aventis, Bridgewater, New Jersey 08807; \\ \#Department of Molecular Biology, Bristol-Myers Squibb Research Institute, Princeton, New Jersey 08540
}

\begin{abstract}
The identification of stem cell/progenitor populations represents a critical step for deducing the putative cell type(s) of origin for epithelial cancers and may provide important therapeutic insights. In the case of the prostate gland, recent studies have made significant progress in the identification of candidate stem cell populations, but they have left unresolved key questions about their tissue localization and functional properties. In our work, we have used genetic lineage marking in vivo to demonstrate that a rare epithelial cell population marked by expression of the Nkx3.1 homeobox gene in the androgen-deprived prostate contains bipotential progenitor cells that are capable of self-renewal. Inducible targeting of the Pten tumor suppressor in these castrate-resistant $\mathrm{Nkx3}$.1-expressing cells demonstrates that this stem/progenitor population is also a potent cell of origin for prostate cancer in mouse models. These findings may help to explain several intriguing features of prostate cancer and its phenotypic progression.
\end{abstract}

The importance of the stem cell compartment as a potential target of oncogenic transformation was appreciated more than three decades ago (Park et al. 1971) and more recently has been highlighted due to substantial evidence supporting the existence of "cancer stem cells" (Reya et al. 2001; Pardal et al. 2003; Wicha et al. 2006). Such putative cancer stem cells can in principle arise through oncogenic transformation of an endogenous stem cell or a downstream lineally related progenitor. Therefore, to identify potential cell types of origin for cancer, it is essential to understand normal lineage relationships during tissue organogenesis and adult homeostasis. Here, we review current work on stem cells and epithelial lineages in the prostate epithelium and present our own studies identifying a stem/progenitor population that is a cell of origin for prostate cancer.

\section{FEATURES OF THE PROSTATE EPITHELIUM}

The rodent prostate is composed of four distinct lobes (anterior, dorsal, lateral, and ventral) that are arranged circumferentially around the urethra at the base of the bladder (Fig. 1A) (Abate-Shen and Shen 2000; Marker et al. 2003). These lobes display characteristic morphological and histological appearances but otherwise behave similarly in most assays for prostate growth and function. In contrast, the human prostate gland lacks a distinct lobular structure, but it does display a zonal architecture that is evident in histological sections (Fig. 1B). The embryological and molecular relationship between the individual prostate lobes of the rodent prostate and the zonal architecture of the human gland has been a subject of considerable debate. Although morphological criteria suggest that
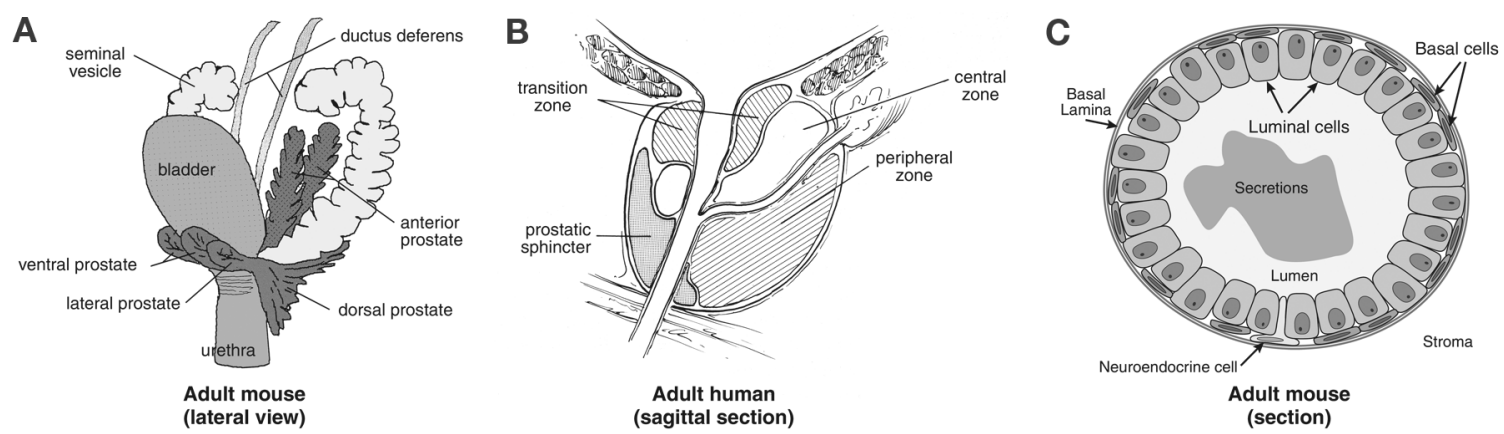

Figure 1. Anatomy of the prostate gland. $(A, B)$ Schematic depiction of the anatomy of the mouse $(A)$ and human $(B)$ prostate gland. $(C)$ Schematic illustration of the primary cell types within a section of a mouse prostatic duct. (Adapted from Abate-Shen and Shen 2000.) 
the dorsal and anterior lobes are most closely related to the human prostate, all four lobes retain histopathological features of the human prostate epithelium.

There are three differentiated epithelial cell types in the mouse and human prostate (Fig. 1C) (Foster et al. 2002; van Leenders and Schalken 2003; Hudson 2004; Peehl 2005). Luminal cells are polarized secretory epithelial cells that produce the protein secretions that fill the lumen of the gland. The luminal epithelium corresponds to a continuous layer of tall columnar cells that express characteristic markers such as cytokeratins 8 and 18, the homeodomain protein $\mathrm{Nkx} 3.1$, and high levels of androgen receptor (AR). Basal cells are located beneath the luminal epithelium, and they express markers such as p63 and cytokeratins 5 and 14 as well as low levels of AR; interestingly, the basal layer is continuous in the human prostate, but it is discontinuous in the mouse prostate (ElAlfy et al. 2000). In addition, a subpopulation of basal cells coexpresses basal and luminal markers and has been termed "intermediate cells" (Verhagen et al. 1988; Bonkhoff et al. 1994; van Leenders et al. 2000; Hudson et al. 2001). Finally, neuroendocrine cells are rare cells that express endocrine markers but not AR. The relationship of neuroendocrine cells to the other two cell types has been unclear, although limited data have suggested that they represent a postmitotic cell type that is derived from luminal secretory cells (Bonkhoff et al. 1991, 1994, 1995).

\section{DEVELOPMENT AND REGENERATION OF THE PROSTATE GLAND}

Circulating testosterone synthesized by Leydig cells of the testis is required for most aspects of prostate induction, organogenesis, and tissue homeostasis. In the mouse, the prostate arises as epithelial buds from the urogenital sinus during late embryogenesis, initiating at 17.5 days postcoitum (dpc). During prostate organogenesis, epithelial cells in the prostatic buds express a combination of basal (p63, cytokeratin 5) and luminal (Nkx3.1) markers, whereas lineage-specific marker expression does not occur until neonatal stages. Following ductal canalization, distinct luminal and basal cell populations can be identified by morphological criteria as well as lineage-specific marker expression. Most ductal outgrowth occurs during before sexual maturity. During these stages, the prostatic ducts undergo extensive proximodistal outgrowth, with cell proliferation primarily occurring distally at the ductal tips (Sugimura et al. 1986a,c).

By early adulthood ( 8 weeks of age), the prostate epithelium is essentially growth-quiescent, with less than $1 \%$ of epithelial cells expressing the proliferation marker Ki67 (Bhatia-Gaur et al. 1999). However, this tight control over epithelial proliferation deteriorates with age, because wild-type mice over 1 year of age frequently display epithelial hyperplasia and in rare cases can develop lowgrade prostatic intraepithelial neoplasia (PIN), a precursor of prostate carcinoma (Kim et al. 2002b). In humans, renewed epithelial proliferation during aging is associated with benign prostatic hyperplasia (BPH) and is also evident in the emergence of PIN.
In the rodent and human prostate, androgen deprivation leads to rapid loss of most luminal cells through apoptosis, whereas the majority of basal cells survive (English et al. 1987; Evans and Chandler 1987b). The cells that undergo apoptosis are preferentially localized to the distal regions of prostatic ducts, whereas proximal ducts are less affected, a pattern that is opposite to the process of ductal outgrowth. Following administration of androgens to castrated rodents by implantation of hormone pellets or osmotic pumps, the prostate will regenerate during a span of approximately 2 weeks, with cellular proliferation occurring in both the basal and luminal compartments (Sugimura et al. 1986b,c; English et al. 1987; Evans and Chandler 1987b). If the source of androgens is subsequently removed, the regenerated prostate will once again fully regress, yet remain capable of androgen-induced regeneration, a process that can be repeated for more than 15 cycles of serial regression/regeneration (Tsujimura et al. 2002).

During prostate regression after androgen deprivation, most of the apoptosis occurs in the luminal population, whereas basal cells are largely unaffected. Thus, the $90 \%$ loss of cells during regression is almost entirely confined to the luminal population. However, substantial numbers of luminal cells still remain in the androgen-deprived state. These luminal cells, as well as the surviving basal cells, appear to be truly castration-resistant, because they persist after further removal of endogenous androgens following adrenalectomy or treatment with AR antagonists such as flutamide in the castrated state.

\section{EVIDENCE FOR STEM CELLS IN THE PROSTATE EPITHELIUM}

Although ample evidence exists for stem cell populations in many adult tissues, it is not evident that all tissues require stem cells for their maintenance and homeostasis. For example, substantial data suggest that tissue regeneration in the liver and pancreas appears to be driven by the proliferation of differentiated cells (Forbes et al. 2002; Dor et al. 2004). Given the growth quiescence of the adult prostate epithelium, it is unclear whether stem cell function is required for normal tissue homeostasis of the prostate gland. However, the observation that the prostate can undergo multiple rounds of serial regression/regeneration in response to androgen deprivation/administration implies the existence of a stem cell population in the prostate epithelium.

This ability of the prostate to undergo serial regression/regeneration implies that epithelial stem cells are castration-resistant, and do not require androgens for their survival. However, the ability of the prostate to regenerate rapidly in response to androgen treatment indicates that stem cells are directly or indirectly androgen-responsive. Notably, the prostate gland differs from other tissues (e.g., epidermis, intestinal epithelium, and hematopoietic system) in which there is a continual need for stem cell activity to maintain tissue homeostasis. Instead, the prostate appears to be more similar to growth-quiescent tissues such as the lung, in which stem cell activity is associated with wound repair and regeneration. 
The proximodistal direction of ductal outgrowth and the predominant localization of proliferating cells to ductal tips during normal organogenesis (Sugimura et al. $1986 a, c)$ suggest that stem cells should be preferentially localized to the proximal region of prostatic ducts (Kinbara et al. 1996). Moreover, explant experiments that involve microdissection of proximal versus medial and distal regions of the prostate ducts provide evidence that the proximal region is indeed enriched for cells with stem cell properties. In particular, cells from the proximal region are able to regenerate prostate ducts in tissue recombination/renal grafting experiments with a 17 -foldhigher efficiency than cells from the distal region, and the proximal grafts can be serially grafted for at least four passages (Goto et al. 2006).

Additional evidence for the existence of stem cells in the prostate epithelium has been provided by assays that use ex vivo tissue recombination followed by renal grafting. When explanted sections of adult prostate ductal tips are combined with embryonic urogenital epithelium in renal grafts, massive proliferation of the epithelial cells occurs in these tissue recombinants (Norman et al. 1986; Kinbara et al. 1996). During 1 month's growth of such tissue recombinants, the number of epithelial cells can expand from 5000 to approximately $3 \times 10^{7}$, representing a 6000-fold increase (Norman et al. 1986; Kinbara et al. 1996; Kim et al. 2002b). This process can be repeated in serial transplantations of epithelium from the tissue recombinants for two additional rounds (Kim et al. 2002b). Interestingly, there appears to be a lower limit to the number of epithelial cells that can be used in these tissue recombinations, because approximately 3000-5000 cells are standardly used for successful grafts, but 600 1000 cells are usually unsuccessful (Norman et al. 1986), suggesting that the grafted epithelium requires the presence of a rare stem cell to proliferate significantly.

\section{LOCALIZATION OF STEM CELLS IN THE PROSTATE EPITHELIUM}

\section{Evidence for a Basal Localization}

Stem cells for the prostate epithelium have traditionally been thought to be located in the basal layer. This localization was originally proposed based on the relative androgen independence and higher proliferative index of basal cells, as well as their heterogeneous patterns of cytokeratin expression (Kyprianou and Isaacs 1988; Bonkhoff et al. 1994; Bonkhoff and Remberger 1996; Hudson et al. 2001). Consistent with this interpretation, studies of primary human prostate epithelial cells explanted into tissue culture have suggested that basal cells can generate luminal progeny, both in culture and following recombination with embryonic mesenchyme and renal grafting (Robinson et al. 1998; Collins et al. 2001; Richardson et al. 2004; Schmelz et al. 2005). Additional evidence has been provided by analysis of an immortalized rat basal cell line that can give rise to luminal cells (Danielpour 1999; Hayward et al. 1999). These and other studies have led to a model in which "intermediate" basal cells represent precursors of luminal cells (Verhagen et al. 1988; Bonkhoff et al. 1994; van Leenders et al. 2000; Hudson et al. 2001). In general, the standard model proposes that a basal subpopulation of stem cells can generate transit-amplifying cells with an intermediate phenotype, and these in turn become precursors of luminal and possibly neuroendocrine cells (Fig. 2A) (Isaacs and Coffey 1989; Bonkhoff and Remberger 1996; Bui and Reiter 1998).

More recent work has used cell surface markers and flow cytometry/immunomagnetic bead approaches to identify candidate stem cell populations in normal mouse and human prostate epithelium, using markers such as CD133 (prominin), CD44, CD49f ( $\alpha 6$ integrin), and Sca-1. For example, $\mathrm{CD} 133^{+} \alpha 2 \beta 1^{\text {hi }}$ cells isolated from the human prostate have been reported to be enriched for clonogenic ability in culture and can form prostatic ducts in renal grafts (Richardson et al. 2004). However, despite the use of CD133 as a specific stem cell marker in a range of tissues, this identification is based on the use of a single monoclonal antibody (AC133) that detects a glycosylation-sensitive epitope that can yield distinct staining patterns under different immunostaining conditions. In particular, a recent study has shown that CD133 is in fact broadly expressed by luminal cells of the colon, lung, and pancreas (although the prostate was not examined) and has questioned the validity of CD133 as a marker for adult stem cells as well as colon cancer stem cells (Shmelkov et al. 2008).

In the mouse prostate, two groups originally reported enrichment for prostate epithelial stem cells among Sca$1^{+}$cells, which represent a heterogeneous population that comprises both luminal and basal cells and corresponds to between $15 \%$ and $20 \%$ of the total prostate epithelial population (Burger et al. 2005; Xin et al. 2005). A followup study further purified the Sca- $1^{+}$population, showing that a Sca- $1^{+} \mathrm{CD} 49 \mathrm{f}^{+} \mathrm{CD} 45^{-} \mathrm{CD} 31^{-}$Ter $119^{-}$population is 60 -fold enriched for stem cells, as assessed by explant culture and tissue recombinant assays (Lawson et al. 2007). In this study, CD49f ( $\alpha 6$ integrin) was reported to be specific for basal cells, although there is no direct evidence that the Sca- $1^{+} \mathrm{CD} 49 \mathrm{f}^{+} \mathrm{CD} 45^{-} \mathrm{CD} 31^{-}$Ter119lation is homogeneous. Most notably, a recent study has reported that $10 \%$ of single cells that are $\mathrm{Lin}^{-} \mathrm{Sca}-$ $1^{+} \mathrm{CD} 133^{+} \mathrm{CD} 44^{+} \mathrm{CD} 117^{+}$are able to reconstitute prostate duct formation following recombination with urogenital mesenchyme and renal grafting (Leong et al. 2008). Interestingly, this study has provided evidence that CD117 (c-kit) may have a critical role in stem cell maintenance and function during prostate regeneration. At present, however, it is unclear whether the $\mathrm{Lin}^{-} \mathrm{Sca}-$ $1^{+} \mathrm{CD} 133^{+} \mathrm{CD} 44^{+} \mathrm{CD} 117^{+}$population is restricted to basal cells, because CD117 is expressed by both basal and luminal cells (Leong et al. 2008).

\section{Evidence for a Luminal Localization}

In contrast, other work has suggested a luminal localization of stem cells, based on the proliferative activity of the luminal layer in the intact, castrated, and regenerating prostate (English et al. 1987; Evans and Chandler 1987a, b; van der Kwast et al. 1998). Interestingly, most cell proliferation in the regressed prostate occurs in the luminal 
A

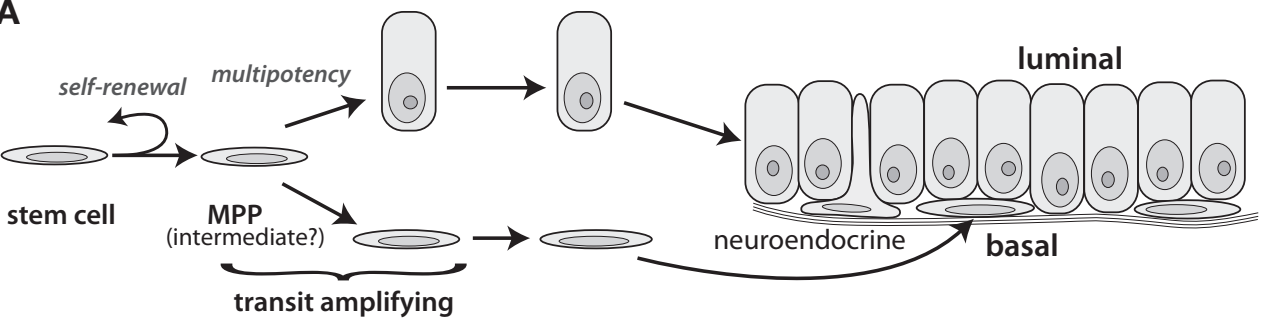

castration-resistant

B

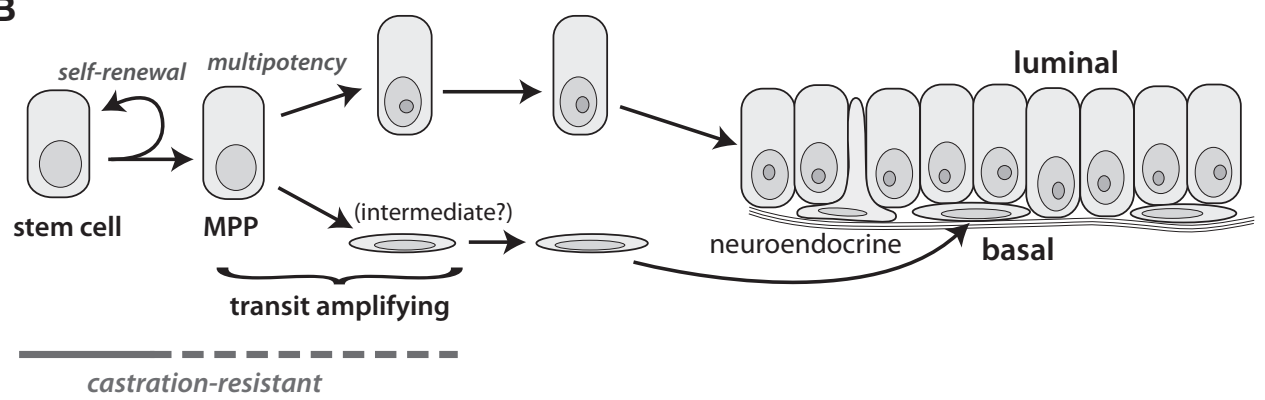

Figure 2. Models for lineage relationships in the prostate epithelium. (A) Conventional lineage model, in which a basal stem cell generates basal and luminal progeny. Intermediate cells correspond to a subset of basal cells that express luminal markers and may represent bipotential progenitors. The lineage relationship of neuroendocrine cells to other cell types is unclear. $(B)$ Alternative model for lineage relationships, suggested by analyses of castration-resistant Nkx3.1-expressing cells (CARNs). In this model, a luminal stem cell may give rise to basal progeny, perhaps via intermediate cells. (MPP) Multipotent progenitor population.

epithelium, suggesting that at least some cells in the luminal compartment may have self-renewal capability (van der Kwast et al. 1998).

In particular, two recent lines of evidence support the notion that prostate stem cells may partially or exclusively reside in the luminal compartment. First, the tissue distribution of putative progenitors has been investigated by examining label-retaining cells (LRCs) generated during serial regression/regeneration of the mouse prostate (Tsujimura et al. 2002). This approach uses pulse-chase labeling with bromodeoxyuridine (BrdU) to identify cells that rarely proliferate and therefore retain BrdU over long periods of time, resulting in an LRC population that is in principle enriched for growth-quiescent stem cells (Bickenbach and Holbrook 1987; Cotsarelis et al. 1989; Morris and Potten 1999; Taylor et al. 2000). LRC populations in many tissues are believed to be enriched for stem cells, although recent work has shown that this is not the case in the hematopoietic system. Nonetheless, the analysis of LRCs generated during prostate regeneration indicated that these cells are preferentially localized to the proximal region of the prostatic ducts (closest to the urethra), consistent with an analysis of distribution of cells with stem cell properties in grafting experiments (Goto et al. 2006). Notably, LRCs are found in both luminal and basal compartments of the prostate epithelium (Tsujimura et al. 2002).

A second line of evidence has emerged from studies of p63-null mutant mice that display neonatal lethality with a complete absence of prostate tissue and lack all basal epithelial cells (Mills et al. 1999; Yang et al. 1999; Signoretti et al. 2000). All urogenital sinus epithelial cells are $\mathrm{p} 63^{+}$before prostate induction, and consistent with this observation, chimera experiments show that all prostate epithelial cells are derived from p63-expressing progenitors (Kurita et al. 2004; Signoretti et al. 2005). However, tissue-grafting experiments demonstrate that prostate tissue can form in explants from $p 63$-null mutant embryos, despite the total lack of basal cells in the resulting tissue (Kurita et al. 2004; Signoretti et al. 2005). These grafted $p 63$ mutant prostate tissues display relatively normal prostate histology, apart from the absence of basal cells and the occasional formation of mucin-producing luminal cells that resemble intestinal epithelium (Kurita et al. 2004; Signoretti et al. 2005). Notably, these $p 63$ mutant prostate tissues can undergo multiple rounds of regression/regeneration in the absence of a basal cell layer (Kurita et al. 2004). These results indicate that the prostate stem cell compartment should at least partially reside within the luminal epithelium, although it remains conceivable that the $p 63$ mutation itself might alter stem cell localization.

In summary, considerable evidence exists in the literature that suggests the localization of prostate epithelial progenitor cells to the basal layer, although these studies do not necessarily identify the same cell populations. In addition, other substantive data support a luminal localization. To date, however, there has been no direct investigation of the lineage relationship between basal and luminal cells in vivo. 


\section{A PROGENITOR POPULATION FOR PROSTATE REGENERATION}

In recent studies, we have identified a novel cell population that contains prostate epithelial progenitors (X. Wang et al., in prep.). We identified this cell population through its unusual androgen-independent expression of the homeodomain protein $\mathrm{Nkx} 3.1$, which is required for proper ductal morphogenesis and secretory protein production (Bhatia-Gaur et al. 1999; Shen and Abate-Shen 2003; Abate-Shen et al. 2008). In the adult prostate, all luminal epithelial cells express Nkx3.1 and a small subpopulation of basal cells likely to correspond to intermediate cells (Fig. 3A,B). Although previous studies in cell culture and in vivo reported that Nkx3.1 expression in prostate epithelial cells is lost in the absence of androgens (Bieberich et al. 1996; Sciavolino et al. 1997; Prescott et al. 1998), we have observed that a rare population of epithelial cells within the castrated prostate expresses Nkx3.1 (Fig. 3C) (X. Wang et al., in prep.). These castration-resistant Nkx3.1-expressing cells (CARNs) are strictly luminal (Fig. 3D,E) and comprise less than $1 \%$ of total epithelial cells in the castrated prostate.

To determine whether these CARNs might correspond to prostate epithelial progenitor cells, we used Cre-recombinase-mediated genetic lineage marking to identify their progeny following prostate regeneration. In this lineage- marking approach, we used an inducible system to introduce a heritable genetic alteration in cells expressing a given promoter, as well as in all descendants of these cells. For this purpose, we generated a knockin allele that places an inducible Cre recombinase under the transcriptional control of the $N k \times 3.1$ promoter (X. Wang et al., in prep.). This inducible $N k \times 3.1^{\text {CreERT2 }}$ allele expresses a fusion protein of Cre with a mutated estrogen receptor $\left(\mathrm{ER}^{\mathrm{T} 2}\right)$ that lacks the DNA-binding domain and fails to bind endogenous estrogens. The resulting CreER ${ }^{\mathrm{T} 2}$ fusion protein is completely inactive in vivo, but it can be rapidly activated by administration of the synthetic ligand tamoxifen (Fig. 3F) (Feil et al. 1997; Indra et al. 1999; Kuhbandner et al. 2000).

To determine whether the CARN population in the castrated prostate contains progenitor cells, we induced Cre activity in castrated $N k x 3.1^{\mathrm{CreERT2/+}} ; R 26 R-Y F P /+$ or $N k x 3.1^{C r e E R T 2 /+} ; R 26 R-L a c Z /+$ adult males with tamoxifen (Fig. 3G) and then initiated prostate regeneration by androgen treatment (X. Wang et al., in prep.). In these regenerated prostates, we observed frequent clusters of yellow fluorescent protein (YFP)-expressing or $\beta$-galactosidase-expressing cells, interspersed with occasional marked cells that had apparently remained solitary (Fig. $3 \mathrm{H})$. The wide dispersion of the lineage-marked clusters suggests that many of these clusters are clonal, representing the progeny arising from a single progenitor during prostate regeneration. Notably, we observed that some lin-
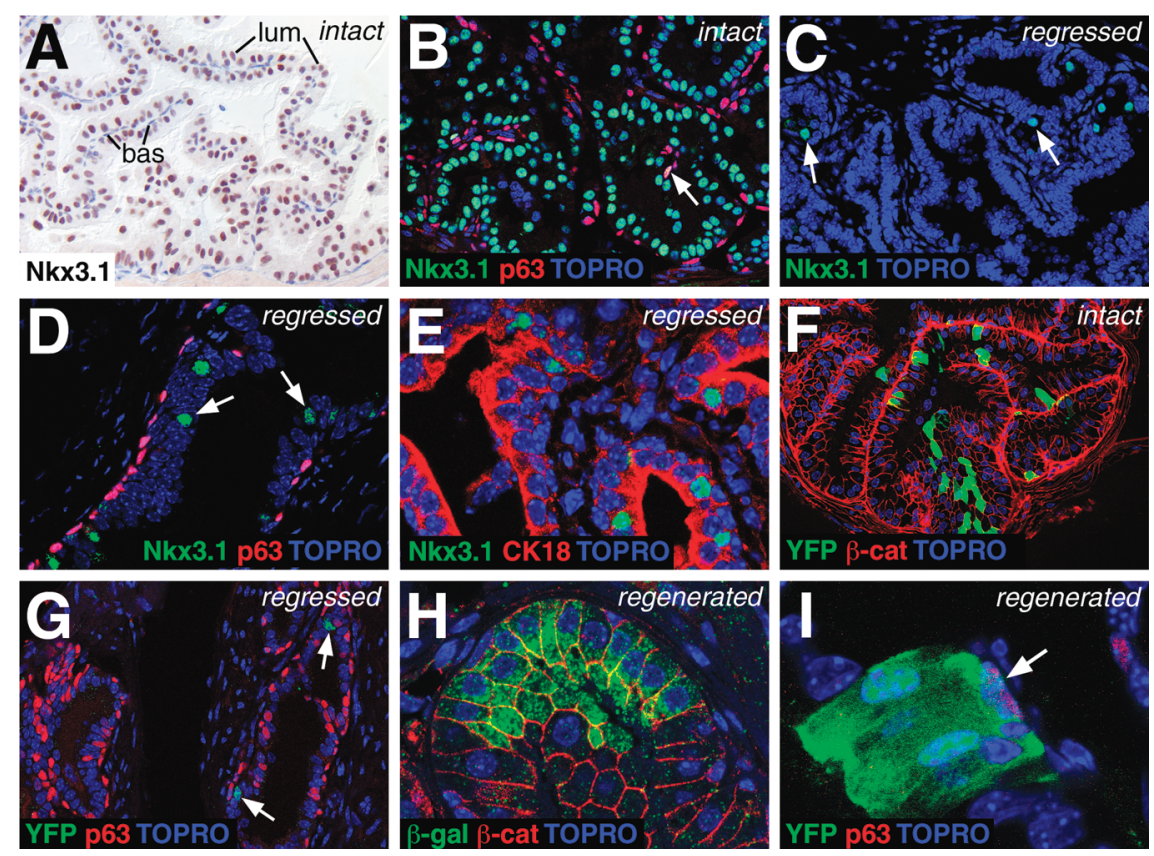

Figure 3. Identification and bipotentiality of castration-resistant Nkx3.1-expressing cells (CARNs). (A) Expression of Nkx3.1 in luminal cells of the anterior prostate from an intact adult male mouse detected by immunohistochemistry. (bas) Basal; (lum) luminal. ( $B$ ) Expression of Nkx3.1 in luminal cells and a subpopulation of basal cells (arrow) in the intact prostate epithelium, as detected by immunofluorescence and confocal imaging. (C) Nkx3.1 is expressed in rare epithelial cells (CARNs, arrows) of the castrated anterior prostate. $(D, E)$ CARNs are strictly luminal, because they never coexpress the basal marker p63 $(D)$ and instead coexpress luminal cytokeratins, such as cytokeratin $18(\mathrm{CK} 18)(E)$. $(F)$ Tamoxifen treatment of intact male mice carrying the inducible $N k x 3.1^{\mathrm{CreERT2}}$ allele together with the R26R-YFP Cre reporter (Srinivas et al. 2001) results in specific yellow fluorescent protein (YFP) expression in the prostate epithelium. $(G)$ Tamoxifen administration to castrated $N k x 3.1^{\mathrm{CreERT2/+}} ; R 26 R-Y F P /+$ male mice results in YFP expression in luminal cells $\left(\mathrm{p} 63^{-}\right)$of the anterior prostate. $(H)$ Androgen administration to castrated and tamoxifen-induced $N k \times 3.1^{\text {CreERT2/ }} ; R 26 R-$ $\mathrm{LacZ} /+$ mice results in extensive proliferation of lineage-marked $\beta$-galactosidase ${ }^{+}$cells in the regenerated anterior prostate. $(I)$ Detection of a lineage-marked $\mathrm{YFP}^{+} \mathrm{p} 63^{+}$basal cell (arrow) following androgen-mediated prostate regeneration in a castrated, tamoxifen-induced $N k x 3.1^{\text {CreERT2/+ }} ; R 26 R-Y F P /+$ mouse. 
eage-marked clusters contained both luminal and basal cells (Fig. 3I). Because the strictly luminal starting population can give rise to a mixed population of luminal and basal cells, we conclude that the CARN population contains bipotential progenitors.

In additional studies, we showed that the prostatic intraepithelial neoplasia phenotype of $N k \times 3.1$ mutants is partially suppressed in a serial regression/regeneration paradigm, suggesting that the number of prostate epithelial stem cells is reduced in $N k \times 3.1$ mutants (X. Wang et al., in prep.). Consistent with these results, we also found that the number of BrdU-label-retaining cells is reduced in $N k x 3.1$ mutants relative to wild type following serial regression/regeneration. Moreover, we have previously observed that the ability of $N k x 3.1$ mutant epithelial cells to proliferate is reduced in serial transplants of tissue recombinants with embryonic urogenital mesenchyme (Kim et al. 2002b; Abate-Shen et al. 2003). Consequently, stem cells are more likely to differentiate in the absence of $N k x 3.1$, leading to an expansion of the highly proliferative transit-amplifying population. Such a model is supported by the observation that the duration of epithelial proliferation during regeneration is significantly prolonged in castrated $N k \times 3.1$ heterozygous and homozygous males relative to wild type, resulting in epithelial hyperproliferation (Magee et al. 2003). Moreover, this interpretation is also consistent with the development of prostatic epithelial hyperplasia in young heterozygous and homozygous Nkx3.1 mice (Bhatia-Gaur et al. 1999). Taken together, these results support a model in which $N k \times 3.1$ is required for prostate stem cell maintenance.

Finally, we have shown that the CARN population corresponds to a cell of origin for prostate cancer in mouse models (X. Wang et al., in prep.). Inducible deletion of the Pten tumor suppressor in CARNS in the regressed prostate of $N k x 3.1^{\text {CreERT2/+ }}$;Pten flox/flox mice results in high-grade $\mathrm{PIN} /$ carcinoma lesions following androgen administration and prostate regeneration (Fig. 4). These lesions display membrane-localized phospho-Akt, greatly increased cellular proliferation, and evidence of microinvasion into the stroma (X. Wang et al., in prep.). These data indicate that the CARN population can represent an efficient target for oncogenic transformation.

In summary, our work differs in significant ways from earlier studies on prostate stem cells. First, we have used genetic lineage marking to identify a candidate stem/multipotent progenitor population (CARNs) that is both extremely rare and highly specific. Second, we have assayed progenitor properties in the context of prostate regeneration, which is known to be relevant to endogenous stem cell function. In contrast, the adult prostate epithelium is essentially growth quiescent during normal prostate homeostasis; thus, assays that rely on explants of adult epithelial cells may be less physiologically relevant. Third, our experiments have been performed in vivo, which may be relevant because many cell types can display greater plasticity when removed from their normal microenvironment and explanted in culture or in tissue recombination assays. Finally, we have shown that the CARN population represents a potential cell of origin for prostate cancer using an in vivo mouse model.

\section{RECONCILING MODELS FOR PROSTATE STEM CELL LOCALIZATION AND LINEAGES}

Taken together, our studies are compatible with a model in which the prostate epithelial stem cell displays a differentiated luminal phenotype and gives rise to both

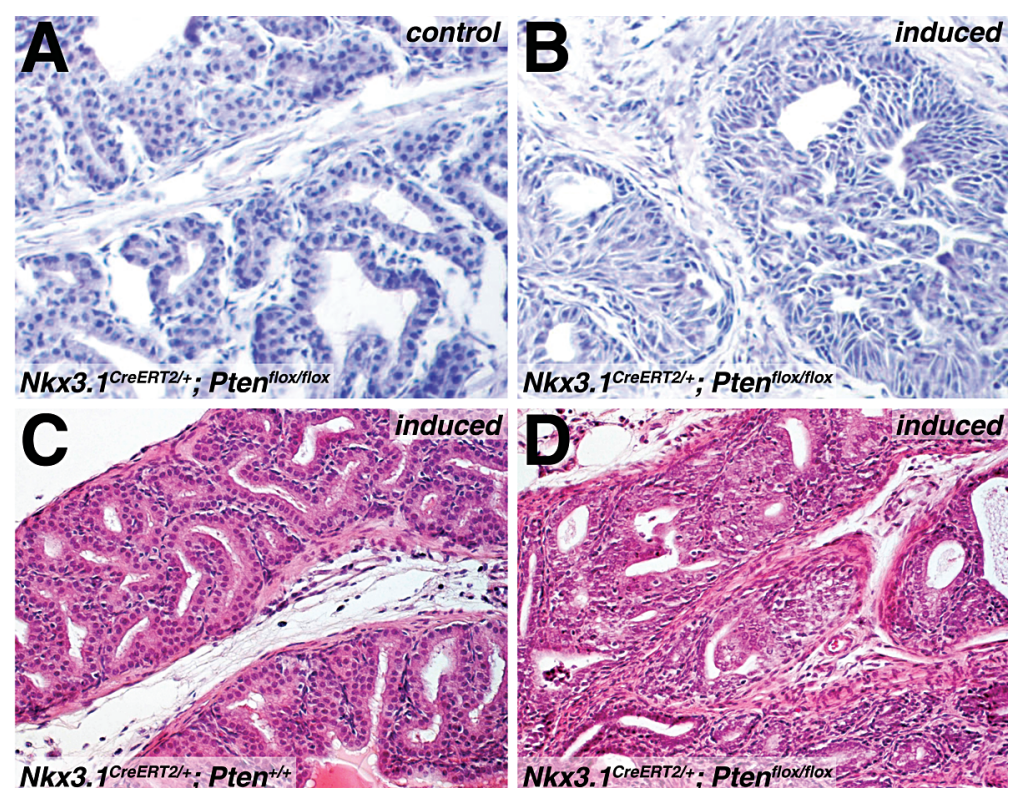

Figure 4. The CARN population is a cell of origin for prostate cancer. $(A, B)$ High-grade prostatic intraepithelial neoplasia (PIN) and carcinoma in castrated, tamoxifen-induced, and regenerated prostate from a Nkx3. CreERT2/+ $_{;}$Pten $^{\text {floxflox }}$ mouse but not in castrated and regenerated prostate from a control mouse of the identical genotype that was not induced with tamoxifen. $(C, D)$ High-grade PIN and

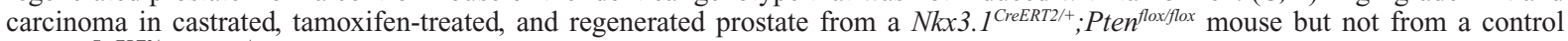
Nkx3.1 CreERT2/+ $_{P^{\prime}}$ ten $^{+/+}$mouse. 
luminal and basal progeny during androgen-mediated regeneration (see Fig. 2B). There may be significant technical reasons why previous studies have not identified luminal stem/progenitor cells in other assays. First, cell culture studies are performed in media that disfavor growth of luminal prostate epithelial cells, which are difficult to culture under conditions that maintain their differentiated phenotype (Peehl 2005). Moreover, flow cytometry experiments necessarily disrupt cell-cell interactions and potential regulation by a putative stem cell niche, which again may interfere with maintenance of a luminal phenotype in culture. Furthermore, the use of Matrigel to provide an extracellular matrix milieu for explant culture/renal grafting analyses may preferentially select for expression of CD44 and CD49f, which both mediate interactions with the extracellular matrix. Consequently, the results obtained for stem cell properties may be highly dependent on the methodologies used, and therefore, putative stem cells identified by one assay may differ from those identified by a distinct assay. In particular, it is not necessarily the case that stem cells for prostate organogenesis will be identical to those used during prostate regeneration.

Overall, our findings are not incompatible with a role for a basal stem cell in the prostate epithelium. Indeed, it is conceivable that there are independent stem cell lineages for basal and luminal cells within the prostate epithelium (Fig. 5). Alternatively, our study may have identified a "potential" stem cell within the prostate epithelium that is responsible for regeneration, perhaps analogous to facultative stem cell populations that have been described to participate in wound healing/regeneration responses in testis and pancreas (Nakagawa et al. 2007; Xu et al. 2008). Such a facultative stem cell population may express differentiation markers and would correspond to transit-amplifying cells that can display stem cell properties during wound healing/regeneration. Indeed, it is possible that two distinct stem cell populations may coexist within the prostate epithelium, one corresponding to an fetal/neonatal progenitor that functions during organogenesis and a second more differentiated population (CARNs) that functions during regeneration; such a model has been recently suggested for the Drosophila tracheal system (Weaver and Krasnow 2008).

\section{CELL OF ORIGIN FOR PROSTATE CANCER}

In principle, cancer can result from transformation of a rare stem cell, leading to the niche-independent dysregulated proliferation of cancer stem cells to generate a tumor or, alternatively, can result from transformation of a more restricted cell type (such as a transit/amplifying cell) and its "dedifferentiation" to acquire self-renewal properties characteristic of stem cells. Evidence for both modes of cancer stem cell generation has been provided by studies of hematopoietic cancers (see, e.g., Cozzio et al. 2003; Huntly et al. 2004; Passegué et al. 2004), but they are less well-studied for solid tumors. Furthermore, the activation of stem cells in chronic injury/wound healing may also serve as a stimulus for stem cell transformation (Beachy et al. 2004). However, the possible existence of cancer stem cells in solid tumors remains contentious (Hill 2006; Visvader and Lindeman 2008).

The cancer stem cell model has several important translational implications. First, this model explains the difficulty in treating a relatively quiescent progenitor population with chemotherapeutic agents that target actively proliferating cells. Second, at least some stem cell populations may have a relatively drug-resistant phenotype due to expression of high levels of ABC family transporter proteins, which correlates with their dye efflux capability (Zhou et al. 2001, 2002; Kim et al. 2002a; Doyle and Ross 2003). Finally, the observation that normal prostate stem cells should be androgen independent raises the possibility that the emergence of androgen-independent prostate cancer might reflect a population shift in the percentage of cancer stem cells within the tumor.

With regard to prostate cancer, it has remained a longstanding conundrum that prostate carcinoma is effectively diagnosed by a complete absence of basal cells (Jiang et al. 2005; Humphrey 2007), whereas prostate epithelial stem cells have been thought to reside in the basal layer. This apparent discrepancy has led numerous studies and reviews to propose either that oncogenic transformation of the basal stem cell leads to its luminal differentiation in tumors or that transformation of a differentiated luminal cell results in the acquisition of stem cell properties. Our findings could potentially resolve this important conundrum because we have shown that the CARN population is luminal and contains stem/multipotent progenitors as

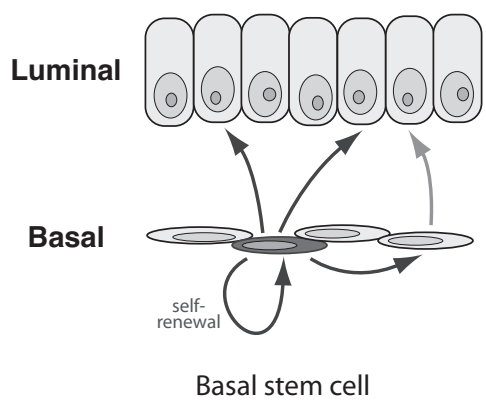

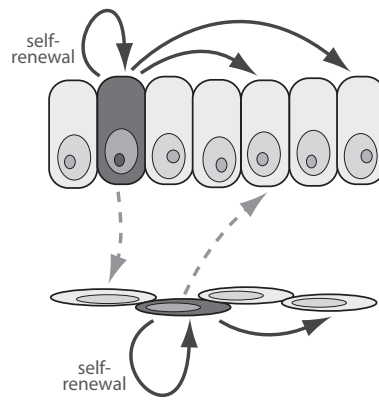

Independent lineages

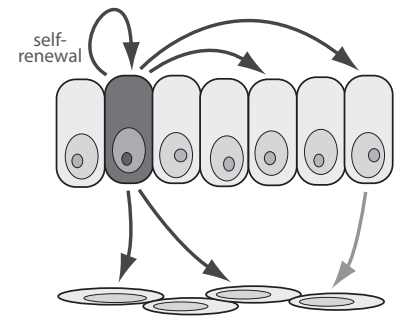

Luminal stem cell

Figure 5. Alternative models for stem cell localization in the prostate epithelium. See text for discussion. 
well as a potential cell of origin for prostate cancer. To the best of our knowledge, our work represents the first demonstration of a prostate epithelial stem cell/multipotent progenitor that can undergo oncogenic transformation to result in prostate cancer in vivo.

\section{ACKNOWLEDGMENTS}

This work was supported by grants from the National Institutes of Health (C.A.-S., M.M.S.), the DOD Prostate Cancer Research Program (K.E., C.A.-S., M.M.S.), and the National Cancer Institute Mouse Models of Human Cancer Consortium. Correspondence should be addressed to mshen@columbia.edu.

\section{REFERENCES}

Abate-Shen, C. and Shen, M.M. 2000. Molecular genetics of prostate cancer. Genes Dev. 14: 2410-2434.

Abate-Shen, C., Shen, M.M., and Gelmann, E. 2008. Integrating differentiation and cancer: The Nkx3.1 homeobox gene in prostate organogenesis and carcinogenesis. Differentiation 76: $717-727$.

Abate-Shen, C., Banach-Petrosky, W.A., Sun, X., Economides, K.D., Desai, N., Gregg, J.P., Borowsky, A.D., Cardiff, R.D., and Shen, M.M. 2003. Nkx3.1; Pten mutant mice develop invasive prostate adenocarcinoma and lymph node metastases. Cancer Res. 63: 3886-3890.

Beachy, P.A., Karhadkar, S.S., and Berman, D.M. 2004. Tissue repair and stem cell renewal in carcinogenesis. Nature 432: 324-331.

Bhatia-Gaur, R., Donjacour, A.A., Sciavolino, P.J., Kim, M., Desai, N., Young, P., Norton, C.R., Gridley, T., Cardiff, R.D., Cunha, G.R., Abate-Shen, C., and Shen, M.M. 1999. Roles for Nkx3.1 in prostate development and cancer. Genes Dev. 13: 966-977.

Bickenbach, J.R. and Holbrook, K.A. 1987. Label-retaining cells in human embryonic and fetal epidermis. J. Invest. Dermatol. 88: $42-46$.

Bieberich, C.J., Fujita, K., He, W.W., and Jay, G. 1996. Prostatespecific and androgen-dependent expression of a novel homeobox gene. J. Biol. Chem. 271: 31779-31782.

Bonkhoff, H. and Remberger, K. 1996. Differentiation pathways and histogenetic aspects of normal and abnormal prostatic growth: A stem cell model. Prostate 28: 98-106.

Bonkhoff, H., Stein, U., and Remberger, K. 1994. Multidirectional differentiation in the normal, hyperplastic, and neoplastic human prostate: Simultaneous demonstration of cell-specific epithelial markers. Hum. Pathol. 25: 42-46.

Bonkhoff, H., Stein, U., and Remberger, K. 1995. Endocrineparacrine cell types in the prostate and prostatic adenocarcinoma are postmitotic cells. Hum. Pathol. 26: 167.

Bonkhoff, H., Wernert, N., Dhom, G., and Remberger, K. 1991. Relation of endocrine-paracrine cells to cell proliferation in normal, hyperplastic, and neoplastic human prostate. Prostate 19: 91-98.

Bui, M. and Reiter, R.E. 1998. Stem cell genes in androgen-independent prostate cancer. Cancer Metastasis Rev. 17: 391-399.

Burger, P.E., Xiong, X., Coetzee, S., Salm, S.N., Moscatelli, D., Goto, K., and Wilson, E.L. 2005. Sca-1 expression identifies stem cells in the proximal region of prostatic ducts with high capacity to reconstitute prostatic tissue. Proc. Natl. Acad. Sci. 102: $7180-7185$.

Collins, A.T., Habib, F.K., Maitland, N.J., and Neal, D.E. 2001. Identification and isolation of human prostate epithelial stem cells based on $\alpha(2) \beta(1)$-integrin expression. J. Cell Sci. 114: 3865-3872.

Cotsarelis, G., Cheng, S.Z., Dong, G., Sun, T.T., and Lavker, R.M. 1989. Existence of slow-cycling limbal epithelial basal cells that can be preferentially stimulated to proliferate: Implications on epithelial stem cells. Cell 57: 201-209.
Cozzio, A., Passegué, E., Ayton, P.M., Karsunky, H., Cleary, M.L., and Weissman, I.L. 2003. Similar MLL-associated leukemias arising from self-renewing stem cells and shortlived myeloid progenitors. Genes Dev. 17: 3029-3035.

Danielpour, D. 1999. Transdifferentiation of NRP-152 rat prostatic basal epithelial cells toward a luminal phenotype: Regulation by glucocorticoid, insulin-like growth factor-I and transforming growth factor- $\beta$. J. Cell Sci. 112: 169-179.

Dor, Y., Brown, J., Martinez, O.I., and Melton, D.A. 2004. Adult pancreatic $\beta$-cells are formed by self-duplication rather than stem-cell differentiation. Nature 429: 41-46.

Doyle, L.A. and Ross, D.D. 2003. Multidrug resistance mediated by the breast cancer resistance protein BCRP (ABCG2). Oncogene 22: 7340-7358.

El-Alfy, M., Pelletier, G., Hermo, L.S., and Labrie, F. 2000. Unique features of the basal cells of human prostate epithelium. Microsc. Res. Tech. 51: 436-446.

English, H.F., Santen, R.J., and Isaacs, J.T. 1987. Response of glandular versus basal rat ventral prostatic epithelial cells to androgen withdrawal and replacement. Prostate 11: 229-242.

Evans, G.S. and Chandler, J.A. 1987a. Cell proliferation studies in rat prostate. I. The proliferative role of basal and secretory epithelial cells during normal growth. Prostate 10: 163-178.

Evans, G.S. and Chandler, J.A. 1987b. Cell proliferation studies in the rat prostate. II. The effects of castration and androgeninduced regeneration upon basal and secretory cell proliferation. Prostate 11: 339-351.

Feil, R., Wagner, J., Metzger, D., and Chambon, P. 1997. Regulation of Cre recombinase activity by mutated estrogen receptor ligand-binding domains. Biochem. Biophys. Res. Commun. 237: 752-757.

Forbes, S., Vig, P., Poulsom, R., Thomas, H., and Alison, M. 2002. Hepatic stem cells. J. Pathol. 197: 510-518.

Foster, C.S., Dodson, A., Karavana, V., Smith, P.H., and Ke, Y. 2002. Prostatic stem cells. J. Pathol. 197: 551-565.

Goto, K., Salm, S.N., Coetzee, S., Xiong, X., Burger, P.E., Shapiro, E., Lepor, H., Moscatelli, D., and Wilson, E.L. 2006. Proximal prostatic stem cells are programmed to regenerate a proximal-distal ductal axis. Stem Cells 24: 1859-1868.

Hayward, S.W., Haughney, P.C., Lopes, E.S., Danielpour, D., and Cunha, G.R. 1999. The rat prostatic epithelial cell line NRP152 can differentiate in vivo in response to its stromal environment. Prostate 39: 205-212.

Hill, R.P. 2006. Identifying cancer stem cells in solid tumors: Case not proven. Cancer Res. 66: 1891-1895.

Hudson, D.L. 2004. Epithelial stem cells in human prostate growth and disease. Prostate Cancer Prostatic Dis. 7: 188-194.

Hudson, D.L., Guy, A.T., Fry, P., O'Hare, M.J., Watt, F.M., and Masters, J.R. 2001. Epithelial cell differentiation pathways in the human prostate: Identification of intermediate phenotypes by keratin expression. J. Histochem. Cytochem. 49: 271-278.

Humphrey, P.A. 2007. Diagnosis of adenocarcinoma in prostate needle biopsy tissue. J. Clin. Pathol. 60: 35-42.

Huntly, B.J., Shigematsu, H., Deguchi, K., Lee, B.H., Mizuno, S., Duclos, N., Rowan, R., Amaral, S., Curley, D., Williams, I.R., Akashi, K., and Gilliland, D.G. 2004. MOZ-TIF2, but not BCR-ABL, confers properties of leukemic stem cells to committed murine hematopoietic progenitors. Cancer Cell 6: 587596.

Indra, A.K., Warot, X., Brocard, J., Bornert, J.M., Xiao, J.H., Chambon, P., and Metzger, D. 1999. Temporally-controlled sitespecific mutagenesis in the basal layer of the epidermis: Comparison of the recombinase activity of the tamoxifeninducible Cre-ER(T) and Cre-ER(T2) recombinases. Nucleic Acids Res. 27: 4324- 4327.

Isaacs, J.T. and Coffey, D.S. 1989. Etiology and disease process of benign prostatic hyperplasia. Prostate Suppl. 2: 33-50.

Jiang, Z., Li, C., Fischer, A., Dresser, K., and Woda, B.A. 2005. Using an AMACR (P504S)/34ßE12/p63 cocktail for the detection of small focal prostate carcinoma in needle biopsy specimens. Am. J. Clin. Pathol. 123: 231-236.

Kim, M., Turnquist, H., Jackson, J., Sgagias, M., Yan, Y., Gong, M., Dean, M., Sharp, J.G., and Cowan, K. 2002a. The multidrug resistance transporter ABCG2 (breast cancer resistance 
protein 1) effluxes Hoechst 33342 and is overexpressed in hematopoietic stem cells. Clin. Cancer Res. 8: 22-28.

Kim, M.J., Bhatia-Gaur, R., Banach-Petrosky, W.A., Desai, N., Wang, Y., Hayward, S.W., Cunha, G.R., Cardiff, R.D., Shen, M.M., and Abate-Shen, C. 2002b. Nkx3.1 mutant mice recapitulate early stages of prostate carcinogenesis. Cancer Res. 62: 2999-3004.

Kinbara, H., Cunha, G.R., Boutin, E., Hayashi, N., and Kawamura, J. 1996. Evidence of stem cells in the adult prostatic epithelium based upon responsiveness to mesenchymal inductors. Prostate 29: $107-116$

Kuhbandner, S., Brummer, S., Metzger, D., Chambon, P., Hofmann, F., and Feil, R. 2000. Temporally controlled somatic mutagenesis in smooth muscle. Genesis 28: 15-22.

Kurita, T., Medina, R.T., Mills, A.A., and Cunha, G.R. 2004 Role of p63 and basal cells in the prostate. Development 131: 4955-4964.

Kyprianou, N. and Isaacs, J.T. 1988. Activation of programmed cell death in the rat ventral prostate after castration. Endocrinology 122: 552-562.

Lawson, D.A., Xin, L., Lukacs, R.U., Cheng, D., and Witte, O.N. 2007. Isolation and functional characterization of murine prostate stem cells. Proc. Natl. Acad. Sci. 104: 181-186.

Leong, K.G., Wang, B.-E., Johnson, L., and Gao, W.-Q. 2008. Generation of a prostate from a single adult stem cell. Nature 456: 804-808.

Magee, J.A., Abdulkadir, S.A., and Milbrandt, J. 2003. Haploinsufficiency at the $N k \times 3.1$ locus. A paradigm for stochastic, dosage-sensitive gene regulation during tumor initiation. Cancer Cell 3: 273-283.

Marker, P.C., Donjacour, A.A., Dahiya, R., and Cunha, G.R. 2003. Hormonal, cellular, and molecular control of prostatic development. Dev. Biol. 253: 165-174.

Mills, A.A., Zheng, B., Wang, X.J., Vogel, H., Roop, D.R., and Bradley, A. 1999. p63 is a p53 homologue required for limb and epidermal morphogenesis. Nature 398: 708-713.

Morris, R.J. and Potten, C.S. 1999. Highly persistent label-retaining cells in the hair follicles of mice and their fate following induction of anagen. J. Invest. Dermatol. 112: 470-475.

Nakagawa, T., Nabeshima, Y., and Yoshida, S. 2007. Functional identification of the actual and potential stem cell compartments in mouse spermatogenesis. Dev. Cell 12: 195-206.

Norman, J.T., Cunha, G.R., and Sugimura, Y. 1986. The induction of new ductal growth in adult prostatic epithelium in response to an embryonic prostatic inductor. Prostate 8: 209-220.

Pardal, R., Clarke, M.F., and Morrison, S.J. 2003. Applying the principles of stem-cell biology to cancer. Nat. Rev. Cancer 3: 895-902.

Park, C.H., Bergsagel, D.E., and McCulloch, E.A. 1971. Mouse myeloma tumor stem cells: A primary cell culture assay. $J$. Natl. Cancer Inst. 46: 411-422.

Passegué, E., Wagner, E.F., and Weissman, I.L. 2004. JunB deficiency leads to a myeloproliferative disorder arising from hematopoietic stem cells. Cell 119: 431-443.

Peehl, D.M. 2005. Primary cell cultures as models of prostate cancer development. Endocr. Relat. Cancer 12: 19-47.

Prescott, J.L., Blok, L., and Tindall, D.J. 1998. Isolation and androgen regulation of the human homeobox cDNA, NKX3.1. Prostate 35: $71-80$.

Reya, T., Morrison, S.J., Clarke, M.F., and Weissman, I.L. 2001. Stem cells, cancer, and cancer stem cells. Nature 414: 105-111.

Richardson, G.D., Robson, C.N., Lang, S.H., Neal, D.E., Maitland, N.J., and Collins, A.T. 2004. CD133, a novel marker for human prostatic epithelial stem cells. J. Cell Sci. 117: $3539-3545$

Robinson, E.J., Neal, D.E., and Collins, A.T. 1998. Basal cells are progenitors of luminal cells in primary cultures of differentiating human prostatic epithelium. Prostate 37: 149-160.

Schmelz, M., Moll, R., Hesse, U., Prasad, A.R., Gandolfi, J.A., Hasan, S.R., Bartholdi, M., and Cress, A.E. 2005. Identification of a stem cell candidate in the normal human prostate gland. Eur. J. Cell Biol. 84: 341-354.

Sciavolino, P.J., Abrams, E.W., Yang, L., Austenberg, L.P., Shen, M.M., and Abate-Shen, C. 1997. Tissue-specific expression of murine $N k x 3.1$ in the male urogenital system. Dev. Dyn. 209: $127-138$.

Shen, M.M. and Abate-Shen, C. 2003. Roles of the Nkx3.1 homeobox gene in prostate organogenesis and carcinogenesis. Dev. Dyn. 228: 767-778.

Shmelkov, S.V., Butler, J.M., Hooper, A.T., Hormigo, A., Kushner, J., Milde, T., St Clair, R., Baljevic, M., White, I., Jin, D.K., et al. 2008. CD133 expression is not restricted to stem cells, and both $\mathrm{CD} 133^{+}$and $\mathrm{CD} 133^{-}$metastatic colon cancer cells initiate tumors. J. Clin. Invest. 118: 2111-2120.

Signoretti, S., Pires, M.M., Lindauer, M., Horner, J.W., Grisanzio, C., Dhar, S., Majumder, P., McKeon, F., Kantoff, P.W., Sellers, W.R., and Loda, M. 2005. p63 regulates commitment to the prostate cell lineage. Proc. Natl. Acad. Sci. 102: 11355-11360.

Signoretti, S., Waltregny, D., Dilks, J., Isaac, B., Lin, D., Garraway, L., Yang, A., Montironi, R., McKeon, F., and Loda, M. 2000. p63 is a prostate basal cell marker and is required for prostate development. Am. J. Pathol. 157: 1769-1775.

Srinivas, S., Watanabe, T., Lin, C.S., William, C.M., Tanabe, Y., Jessell, T.M., and Costantini, F. 2001. Cre reporter strains produced by targeted insertion of EYFP and ECFP into the ROSA26 locus. BMC Dev. Biol. 1: 4.

Sugimura, Y., Cunha, G.R., and Donjacour, A.A. 1986a. Morphogenesis of ductal networks in the mouse prostate. Biol. Reprod. 34: 961-971.

Sugimura, Y., Cunha, G.R., and Donjacour, A.A. 1986b. Morphological and histological study of castration-induced degeneration and androgen-induced regeneration in the mouse prostate. Biol. Reprod. 34: 973-983.

Sugimura, Y., Cunha, G.R., Donjacour, A.A., Bigsby, R.M., and Brody, J.R. 1986c. Whole-mount autoradiography study of DNA synthetic activity during postnatal development and androgen-induced regeneration in the mouse prostate. Biol. Reprod. 34: 985-995.

Taylor, G., Lehrer, M.S., Jensen, P.J., Sun, T.T., and Lavker, R.M. 2000. Involvement of follicular stem cells in forming not only the follicle but also the epidermis. Cell 102: 451-461.

Tsujimura, A., Koikawa, Y., Salm, S., Takao, T., Coetzee, S., Moscatelli, D., Shapiro, E., Lepor, H., Sun, T.T., and Wilson, E.L. 2002. Proximal location of mouse prostate epithelial stem cells: A model of prostatic homeostasis. J. Cell Biol. 157: 1257-1265. van der Kwast, T.H., Tetu, B., Suburu, E.R., Gomez, J., Lemay, M., and Labrie, F. 1998. Cycling activity of benign prostatic epithelial cells during long-term androgen blockade: Evidence for self-renewal of luminal cells. J. Pathol. 186: 406-409.

van Leenders, G., Dijkman, H., Hulsbergen-van de Kaa, C., Ruiter, D., and Schalken, J. 2000. Demonstration of intermediate cells during human prostate epithelial differentiation in situ and in vitro using triple-staining confocal scanning microscopy. Lab. Invest. 80: 1251-1258.

van Leenders, G.J. and Schalken, J.A. 2003. Epithelial cell differentiation in the human prostate epithelium: Implications for the pathogenesis and therapy of prostate cancer. Crit. Rev. Oncol. Hematol. (suppl.) 46: S3-S10.

Verhagen, A.P., Aalders, T.W., Ramaekers, F.C., Debruyne, F.M., and Schalken, J.A. 1988. Differential expression of keratins in the basal and luminal compartments of rat prostatic epithelium during degeneration and regeneration. Prostate 13: 25-38.

Visvader, J.E. and Lindeman, G.J. 2008. Cancer stem cells in solid tumours: Accumulating evidence and unresolved questions. Nat. Rev. Cancer 8: 755 .

Weaver, M. and Krasnow, M.A. 2008. Dual origin of tissue-specific progenitor cells in Drosophila tracheal remodeling. Science 321: 1496-1499.

Wicha, M.S., Liu, S., and Dontu, G. 2006. Cancer stem cells: An old idea-A paradigm shift. Cancer Res. 66: 1883-1896.

Xin, L., Lawson, D.A., and Witte, O.N. 2005. The Sca-1 cell surface marker enriches for a prostate-regenerating cell subpopulation that can initiate prostate tumorigenesis. Proc. Natl. Acad. Sci. 102: 6942-6947.

Xu, X., D’Hoker, J., Stange, G., Bonné, S., De Leu, N., Xiao, X., Van de Casteele, M., Mellitzer, G., Ling, Z., Pipeleers, D., et al. 2008. $\beta$ Cells can be generated from endogenous progenitors in injured adult mouse pancreas. Cell 132: 197-207. 
Yang, A., Schweitzer, R., Sun, D., Kaghad, M., Walker, N., Bronson, R.T., Tabin, C., Sharpe, A., Caput, D., Crum, C., and McKeon, F. 1999. p63 is essential for regenerative proliferation in limb, craniofacial and epithelial development. Nature 398: $714-718$

Zhou, S., Morris, J.J., Barnes, Y., Lan, L., Schuetz, J.D., and Sorrentino, B.P. 2002. Bcrpl gene expression is required for normal numbers of side population stem cells in mice, and confers relative protection to mitoxantrone in hematopoietic cells in vivo. Proc. Natl. Acad. Sci. 99: 12339-12344.

Zhou, S., Schuetz, J.D., Bunting, K.D., Colapietro, A.M., Sampath, J., Morris, J.J., Lagutina, I., Grosveld, G.C., Osawa, M., Nakauchi, H., and Sorrentino, B.P. 2001. The ABC transporter Bcrp1/ABCG2 is expressed in a wide variety of stem cells and is a molecular determinant of the side-population phenotype. Nat. Med. 7: 1028-1034. 


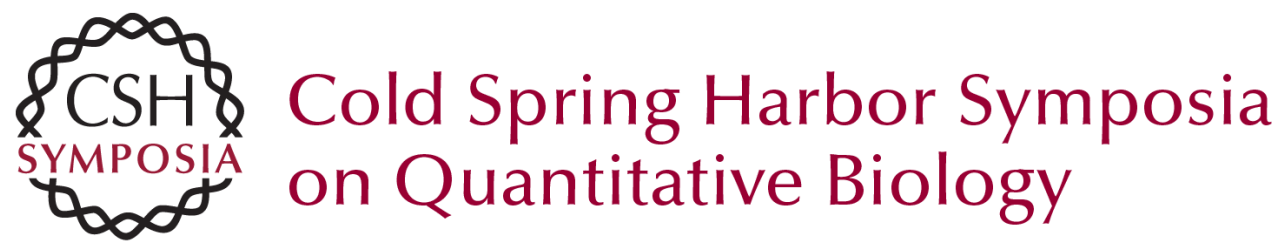

\section{Progenitor Cells for the Prostate Epithelium: Roles in Development, Regeneration, and Cancer}

M.M. Shen, X. Wang, K.D. Economides, et al.

Cold Spring Harb Symp Quant Biol 2008 73: 529-538 originally published online January 15, 2009

Access the most recent version at doi:10.1101/sqb.2008.73.050

References This article cites 82 articles, 22 of which can be accessed free at:

http://symposium.cshlp.org/content/73/529.full.html\#ref-list-1

\section{License}

Email Alerting Receive free email alerts when new articles cite this article - sign up in the box at the Service top right corner of the article or click here. 